\title{
Folia Phoniatrica \\ et Logopaedica
}

Bagnall, A. 158

Bartolome, G. 172

Behrendt, W. 261

Böckler, R. 243

Bouvry, S. 124

Bressmann, T. 272

Busch, R. 272

Coster, F.W. 99

Dalalakis, J.E. 20

Feenstra, L. 117

Fuchs, M. 261

Fujiu-Kurachi, M. 147

Fukuda, S. 36

Fukuda, S.E. 36

Giovanni, A. 108

Goorhuis-Brouwer, S.M. 99

Gopnik, M. 5

Hacki, T. 243

Heulens, H. 117

Horch, H.-H. 272

Kahrilas, P.J. 91

Keller, E. 261

Kessler Robb, M. 55

Kratzsch, J. 261

Langmore, S.E. 220

Lembrechts, D. 117

Logemann, J.A. 91, 145, 199

Mayo, R. 250

Merk, M. 272
Nakken, H. 99

O'Donoghue, S. 158

Ohmae, Y. 91

Pauloski, B.R. 91

Perry, A. 231

Piggott, G.L. 55

Rademaker, A.W. 91

Revis, J. 108

Rose, Y. 70

Royle, P. 70

Sader, R. 272

Schröter-Morasch, H. 172

Shin, T. 213

Smith Hammond, C. 250

Spelberg, H.C.L. 99

Takagi, S. 213

Triglia, J.-M. 108

Troppmann, N. 172

Tsuda, K. 213

Valkenburg, H.A. 117

Van Borsel, J. 124

Verniers, I. 124

Verschueren, D. 117

Warren, D.W. 250

Watkin, K.L. 183

Wuyts, F. 108

Zajac, D. 250

Zeilhofer, H.-F. 272

Ziegler, W. 172, 272 